\title{
Kozmetik Ürünlerin Göz İrritasyon Potansiyellerinin Değerlendirilmesinde Geleneksel ve Alternatif Yöntemler
}

\author{
Özge Köse, Pınar Erkekoğlu, Suna Sabuncuoğlu, Belma Koçer-Gümüşel
}

\section{ÖZET}

Göze uygulanan birçok ilaç ve kozmetik ürünlerin tehlike potansiyellerinin değerlendirilmesinde uzun yıllar boyunca in vivo oküler toksisite testleri kullanılmıştır. Etik açıdan düşünüldüğünde, göz irritasyon testlerinin laboratuvar hayvanları üzerinde yapılması, hayvanlara önemli derecede rahatsılık ve acı verme potansiyeline sahiptir. 3R ilkelerinin yayınlanmasından bu yana kimyasal maddelerin ve kozmetiklerin potansiyel toksik etkilerinin değerlendirilmesi için, birçok alternatif yöntem geliştirilmiş, valide edilmiş ve düzenleyici kuruluşlar tarafından kabul edilmiştir. 11 Mart 2013 tarihinde Avrupa Birliği'nde hayvanlar üzerinde test edilen her tür kozmetik ve kişisel bakım ürününün satışı yasaklanmıştır.
Belirtilen tarihten sonra kozmetik ürünlerin güvenlilik değerlendirmelerinde alternatif in vitro toksisite testleri kullanılmaya başlanmıştır. Kimyasal madde ve kozmetiklerin göz irritasyon potansiyellerinin değerlendirilmesinde alternatif yöntem olarak in vitro yeniden yapılandırılmış insan oküler doku modelleri kullanılmaktadır. Bu modellerden bazıları insan gözüne morfolojik ve fizyolojik olarak benzer olması nedeni ile daha çok tercih edilmektedir. $\mathrm{Bu}$ derlemede, in vitro ve in vivo oküler toksisite testlerinden söz edilecek, yeni geliştirilen ve valide edilen testler kapsamlı bir bakış açısı ile değerlendirilecektir.

Anahtar Kelimeler: Alternatif yöntemler, in vitro, göz irritasyonu, kozmetik ürünler
Belma Koçer-Gümüşel

Hacettepe Üniversitesi, Eczacilı Fakültesi, F.Toksikoloji Anabilim Dall, Sihhiye Ankara Türkiye

Sorumlu Yazar:

Belma Koçer-Gümüşel

e-mail:belmagumusel@yahoo.com

Submitted / Gönderilme: 18.09.2016 Revised / Düzeltme: 17.10.2016

Accepted / Kabul: $\quad 18.10 .2016$

\section{GİRİ̧}

Göz, birçok farklı hücre tipinden meydana gelen karmaşı bir organdır. Gözün dış bariyeri olan kornea ve konjunktiva, irritan maddelere maruziyet sonrası en çok etkilenen kısımlardır (1). Dış çevre ile doğrudan temas halinde olan oküler yüzey oldukça duyarlı bir fizyolojik yapıya sahiptir ve birçok toksik kimyasal maddeye teması söz konusudur. Fiziksel, biyolojik ve kimyasal birçok etmen korneada hasar yaratabilir; oluşturdukları irritasyon ve inflamasyon gözde hasar yaratarak körlüğe neden olabilir. Bu tip kimyasal maddelere örnek olarak evde kullanılan temizlik ürünleri ve kişisel bakım için kullanılan ürünler, endüstride ve tarımda kullanılan kimyasal maddeler verilebilir (2). Bu tür maddelere bilerek ya da bilmeyerek maruz kalma durumları olsa da, genellikle en çok görülen göz hasarları iş ya da ev ortamında çamaşır suyu ve deterjan gibi konsantre çözeltilerin göze teması ile olmaktadır (3).

Tehlikeli maddelere maruziyet riskini azaltmak için bütün tüketici ürünleri ve içerikleri test edilmelidir ve 
göz irritasyon potansiyeli değerlendirilerek güvenliliği konusunda teminat verilmeli ya da ilgili tehlike durumları için uyarılar konulmalıdır. Göz toksisite testleri; ürünlerle ilgili risklerin tanımlanması, uygun güvenlik kriterlerinin karşılanması ve açıkça etiketlenmesi için gereklidir (4).

Geçmiş yıllarda, in vitro testlerin yaygın ve yeterince gelişmiş olmaması nedeniyle deney hayvanları daha yüksek oranda kullanılmıştır (5). Ancak, ilerleyen yıllarda deney hayvanı kullanımına ilişkin etik düzenlemeler yeniden yapılandırılmıştır ve 1959 yılında Ruusel ve Burch tarafından 3R kuralının (azaltma, yerine koyma, iyileştirme) sistematik temeli ortaya konmuştur $(5,6)$. Daha sonraki ylllarda da, in vivo çalışmalar yerine ex vivo ve in vitro alternatif yöntemler geliştirilmeye başlanmıştır (5).

\section{AVRUPA BİRLİĞİ KOZMETIKK MEVZUATI}

\subsection{Kozmetik Ürün Tanımı}

Avrupa Birliği 76/768/EEC sayılı Direktifinin birinci maddesine göre; kozmetik ürünler, insan vücudunun diş yüzeyi (epidermis, saç, tırnak, dudak ve diş genital organ), ağız boşluğunun mukoz membranları ve dişler ile temas halinde olan temizleme, koku önleme, güzel koku verme ve görünüşünü değiştirme amacıyla kullanılan herhangi bir madde veya karışımları olarak tanımlanır (7).

Bitki, hayvan ve mineral kaynaklardan elde edilen çeşitli maddeler kullanılarak üretilen kozmetik ürünlerin binlerce yılı kapsayan bir geçmişi vardır. Günümüzde modern teknoloji ile bu kaynaklara sentetik ve yarı sentetik kökenli ürünler de eklenmiştir (8).

\subsection{Kullanıcı Güvenliliği}

Piyasaya sürülen bir kozmetik ürünün normal veya makul kullanım koşullarında insan sağlığına zarar vermeyecek nitelikte olması gerektiği Direktif 76/768/EEC (md. 2)'de belirtilmiştir (7). Bu gereklilik üretici firmanın sorumluluğundadır (9). Kozmetik ürünün "Teknik Bilgi Dosyası ve Ürün Bilgi Dosyası” güvenlilik dosyası içindeki kimyasal maddelerin yapıları, ürünün kalitatif ve kantitatif bileşimi, kozmetik ürünün ve bileşenlerinin fiziko-kimya, mikrobiyoloji ve saflık kontrolleri, toksikolojik profilleri, bitmiş kozmetik ürünün güvenlilik değerlendirmesi, üretim yöntemi ve günlük maruziyet düzeylerini içermeli ve güvenlik değerlendirmesi yapan kişinin adı ve adresini bulundurmalıdır $(9,10)$. Ürüne ait toksikolojik profil sunulurken, göze temas etmesi söz konusu ürünler için göz irritasyonuna ait bilgilerin de bulunması gereklidir.

\section{DRAİZE GÖZ İRRİTASYON TESTİ}

Deney hayvanları 18. yüzyıldan itibaren göze zararlı olduğu düşünülen maddelerin etkilerini incelemek ve değerlendirmek için kullanılmıştır (2). 1930larda kullanılan bazı kozmetik ürünlerin kalıcı göz hasarlarına neden olduğunun belirlenmesinin ardından 1940 yılında Draize tarafından in vivo Draize Göz İrritasyon Testi (11) geliştirilmiş ve bu test Amerikan Gıda ve İlaç Dairesi (Food and Drug Administration-FDA) tarafından onaylanmıştır $(11,12)$.

Draize testi Ekonomik Kalkınma ve İşbirliği Örgütü (Organisation for Economic Co-operation and Development-OECD) tarafından da kabul edilmiş valide bir test yöntemidir (OECD TG 405) $(13,14)$. Bu protokolde büyük gözleri olması, anatomi ve fizyolojisi iyi tanımlanmış olmaları, ucuz ve kolay elde edilebilir olmaları nedeniyle Yeni Zelanda tavşanları kullanılmaktadır $(13,14)$. Testin pratik olarak uygulanmasında $0.1 \mathrm{ml}$ sivı ve ya $0.1 \mathrm{~g}$ katı test maddesi kornea ve gözün zar kesesine 72 saat boyunca uygulanır (11). Her test için en az 6 tavşan kullanılır, ancak ciddi derecede göz hasarı beklenen durumlarda hayvan sayısı azaltılarak 3 ya da tek bir tavşana indirilir. Şiddetli lezyon saptanan hayvanlara ötenazi uygulanır. Yayınlanan son kılavuza göre Draize testinde hayvanların acı ve 1stıraplarını azaltmak için analjezik ve anestezik ilaçlar uygulanmaktadır (14). Tavşanın gözünde kızarıklık, ödem, kanama, şişme gibi irritasyon bulguları 21 gün boyunca seçilen aralıklarla gözlenir $(13,14)$. Şiddetli göz irritasyonu görülen durumlarda, 21 günlük deney süresi bitmeden bu hayvanlar deneyden çıartılır ya da ötenazi uygulanır (14). Gözlenen irritasyon derecesi kimyasal maddelerin sınıflandırılmasını sağlar. Kornea, konjonktiva ve iris üzerindeki irritan etkileri "irritan olmayan"dan "şiddetli irritan”a kadar kademeli olarak sınıflandırılır. Geri dönüşsüz ve geri dünüşlü oküler hasarlar, bu test kullanılarak tespit edilebilir (15).

Draize testi tekrarlanabilir olmayışı, test süresinin uzunluğu, son noktanın değerlendirilmesindeki sübjektiflik, test maddesinin uygulanmasındaki zorluklar, yüksek doz ve türler arasındaki farklılıklar nedeniyle uzun yıllardır eleştirilmektedir $(16,17)$. Bu testte sıvı ve katı maddelerin göz üzerine uygulanmasında iyi tanımlanamamış farklı temas süreleri vardır (18). Draize testi kornea, iris veya 
konjonktivada birincil ya da ikincil cevaplarla ilgili sınırlı bilgi vermektedir (19). Tavşan gözünün anatomisinin, fizyolojik ve biyokimyasal özellikleri yönünden insan gözünden farklı olması nedeniyle, irritan maddelere duyarlılı̆̆g değişkenlik göstermektedir. İnsanlara göre, tavşan korneası daha ince olup, tavşan gözünde daha az gözyaşı üretilir. Tavşanların göz kırpma sıklı̆̆ı ve oküler yüzey hassasiyeti insanlara oranla daha fazladır (13). Ayrıca, tavşan gözü daha büyük konjunktival keseye ve oküler yüzeyden test maddesinin uzaklaştırılmasını sağlayan üçüncü bir göz kapağına sahiptir (12).

Draize testinin yanısıra göz irritasyonunun değerlendirilmesinde kullanılan; Alternatif Yöntemler Validasyonları Koordinasyon Komitesi tarafından retrospektif validasyonları yapılan ve Alternatif Yöntemler Validasyonu Avrupa Merkezi (The European Union Reference Laboratory for alternatives to animal testing EURL ECVAM) tarafindan onaylanan farklı in vivo ve ex vivo yöntemler de bulunmaktadır.

\section{ALTERNATİ In vivo TESTLER}

\subsection{Düşük Hacimli Göz İrritasyon Testi (Low-volume eye irritation test, LVET)}

Düşük hacimli göz irritasyon testleri (LVET) Ulusal Araştırma Konseyi (20) tarafından verilen tavsiye üzerine Griffith ve ark. (21) tarafından geliştirilmiştir. Draize testinden farkı ise, test maddelerinin düşük hacimlerde $(0.01 \mathrm{ml} / 0.01 \mathrm{~g})$ (22) tavşanın sağ gözüne uygulanmasıdır. Uygulama sırasında göz kapağını açık tutması için deney hayvanı zorlanmaz (19). Test maddesi sadece kornea yüzeyine uygulanır; konjunktiva yüzeyine uygulanmaz. Bu testin deney hayvanlarında daha az strese neden olduğuna inanılmaktadır (23). Patolojik değişiklikler iris, kornea ve konjonktiva ile karakterize edilir (19). LVET özellikle kozmetik, farmasötik ve ev ürünlerinde bulunan surfaktan bazlı karışımlar için uygulanmaktadır (16). Şiddetli irritan maddelerin analizlerinde LVET ve Draize testlerinden elde edilen sonuçlar arasında farklılıklar olduğu gözlenmiştir. Draize testi elde edilen cevapların insanlardan elde edilenlere göre daha abartılı olması yönüyle eleştirilmiş, LVET testinin ise Draize testine göre daha doğru sonuçlar verdiği belirtilmiştir (24-26). Ancak LVET testi de, deney hayvanlarının kullanılması nedeniyle uzun yıllardır eleştirilmektedir. ECVAM, LVET testini Draize testinin yerine kullanılabilecek bir yöntem olarak değerlendirmiş, ancak göz güvenliği için Draize testinin yerini alabilecek bir yöntem olarak kabul etmemiştir (27). Sonuç olarak, LVET herhangi bir düzenleyici kuruluş tarafından alternatif test olarak henüz onay almamıştır. $(28,29)$.

\section{2 İnsan Verileri}

Göz irritasyon testlerinin "altın standartı" insanlardan elde edilen verilerdir (30). Deneklere uygulanacak test gerçekçi koşullar altında yapılmalıdır ve etkiler değerlendirilmelidir (31). Ancak, bu test etik olarak kabul edilmemektedir. Dolayısıyla, maddelerin oluşturabileceği potansiyel göz hasarının belirlenmesinde insan çalışma verileri olarak, kazara maruziyet verileri ve klinik çalışmalar sonucu elde edilen sonuçlar kullanılabilir. Kazara maruziyetten sonra hemen gözün yıkanması nedeniyle, elde edilen veriler her zaman gerçekçi olmayabilir. Ayrıca, göz doktorları ve acil servis klinisyenleri toplanan verileri kaydetmeyebilir. Seyreltilmemiş ürünler kullanılarak gerçekleşen klinik çalışmalar bilimsel ve etik kaygılara yol açmaktadır. Klinik çalışmalarda in vivo tavşan çalışmalarında olduğu gibi test maddesi, alt ve üst konjunktival keseye uygulanır. Ancak, insan çalışmaları irritasyondan daha çok "acı hissi" durumunu araştırmaktadır (28).

1980'li yıllarda gerçekleştirilen çalışmalarda insanda kazara maruziyet verileri ile Draize ve LVET testleri karşılaştırılmıştır. $\mathrm{Bu}$ çalışmalarda kazara maruziyet (genellikle şampuan, el sabunu ve/veya yumuşatıcılara) verileri toplanı, in vivo hayvan deneyleri ile insan maruziyet etkileri arasındaki ilişki araştırılmıştır (24, 25, 28). Draize testinin insanda kazara göz maruziyeti için zayıf kestirimlerde bulunduğu ve insan verilerine göre daha abartılı cevapların alındığı gözlenmiştir. LVET testinin ise, insan verileriyle korelasyonunun daha iyi olduğu belirlenmiştir. Validasyon çalışmalarında insan test verilerinin yeterli olmamasından dolayı, in vitro toksisite çalışmalarının hala tavşan verileri ile karşılaştırılması bir sorun olarak görülmektedir (30).

\section{Ex vivo TESTLER}

OECD tarafından Draize göz testine alternatif yöntem olarak kabul edilen iki test: izole tavuk gözü testi (ICE: Isolated Chicken Eye Test) ve sığır korneası opasite ve geçirgenlik testidir (BCOP: Bovine Cornea Opacity Permeability) (32, 33). Ayrıca, ex vivo izole tavşan gözü testi (IRE: Isolated Rabbit Eye Test-Draize Test), HET-CAM (Tavuk Yumurtası - Koryoallantoik Membran Testi/Hen's Egg Test- Chorio 
Allantoic Membrane) testleri gibi ex vivo yöntemler ile in vitro kornea eşdeğeri yeniden yapılandırılmış doku modelleri kimyasal maddelerin göz irritasyon potansiyelini değerlendirilmek için geliştirilmiş yöntemlerdir (34-39).

Daha yakın zamanda, Sitosensör Mikrofizyometre$\left(\mathrm{CM}^{\mathrm{m}}\right)$ ve Fluorescein Leakage $(\mathrm{FL})$ testi suda çözünebilen test maddeleri için göze korozif ve şiddetli irritasyona neden olan maddeleri tanımlamak için onaylanmıştır. FL test yöntemine ait OECD test kılavuzu 2012 yllında yayınlanmıştır (39). In vitro test yöntemi olan CM ise irritan ve irritan olmayan maddelerin ayrımının sağlanmasında kullanılmış ve valide bir yöntem olarak kabul edilmiştir.

\section{1 İzole / Organotipik yöntemler}

Oküler organotipik modeller, göz veya korneanın fizyolojik ve biyokimyasal fonksiyonlarının kısa süreli olarak sürekliliğini sağlayan izole sistemlerdir (15). Bu testlerde test maddesinin genellikle seyreltilmeden uygulanmasi, insandan elde edilen kazara maruziyet sonuçlarına göre daha güvenilir sonuçlar vermektedir (40).

Protokolde test materyalinin uygulanmasını takiben, izole korneada kantitatif değişikliklerin histolojik analizinde opasitometrik ve spektroskopik yöntemler kullanılır. Kornea donukluğu (opasitesi), epitelde ve korneal stromada hasar, protein denatürasyonu, şişlik ve vakuolizasyonun göstergesi olarak kabul edilir. Ancak, opasite ölçümleri, sübjektif gözlemsel verilere dayanır (15). Diğer taraftan, ex vivo yöntemlerde Fluorescein Leakage testi de korneadan penetrasyonun ölçüldüğü diğer bir testtir. Ayrıca, bu yöntemlerde kornea şişliği ve gözdeki histopatolojik değişiklikler de değerlendirilir (32). In vivo testlerin aksine, bu testlerde değerlendirilen kornea şişliği ve donukluğunun bir skorlama yardımıyla kantitatif olarak değerlendirilmesi daha objektif veriler sağlar ve laboratuvarlar arası varyasyonların azalmasina yardımcı olur. Elde edilen sonuçlar daha sonra göz irritasyon derecesinin belirlenmesi için kullanılır. Genellikle, çok hafif irritan maddeler epitel yüzeyinde, hafif irritanlar penetre olarak stromada, şiddetli irrritanlar ise daha çok penetre olarak kornea ve endotelde hasara neden olur (23).

Oküler organotipik modeller (Enucleated Eye Tests-EET) izole hayvan gözlerinin kullanıldığı modellerdir (41). İzole tavşan gözü testi (Isolated Rabbit Eye Test, IRE testi) tavşan enüklee göz testi (Rabbit Enucleated Eye Test-REET) olarak da bilinmekte olup, başlangıçta gözde geri dönüşümsüz hasara neden olan şiddetli irritanların belirlenmesi için geliştirilmiştir (42). Genelde IRE testinde en sık kullanılan maddeler aktif farmasötik bileşikler, temizlik maddeleri, sabun ve deterjanlar, çözücüler ve surfaktanlardır (41). Farklı laboratuvarlarda IRE protokollerinde kullanılan kontrol sayıları, sinıflandırma sistemi ve metodolojileri modifiye edilmiştir (41). IRE testi, farklı düzenleyici kuruluşlar tarafından değerlendirilmiş olmasına karşın, henüz valide edilmiş bir yöntem değildir (42). IRE testinin toksikolojide optimizasyon çalışmalarında kullanılması tavsiye edilmektedir (41).

ICE testi, test maddelerinin göz irritasyon potansiyelini değerlendirmede yaygın olarak kullanılan ve güvenilir olduğu belirtilen bir testtir (18). ICE, genellikle Draize testinin ön taraması olarak kabul edilir. ICE test protokolü (43) IRE testine benzer bir test olup ilk olarak Prinsen ve Koëter tarafından geliştirilmiştir. Sağlam tavuklardan izole edilen tavuk gözü, 10 saniye içinde kelepçe içine konumlandırılır ve korneanın dikey kalması sağlanır. Takiben $32^{\circ} \mathrm{C}$ 'de 2-3 saniyede bir serum fizyolojik damlatarak 45 dakika aklimatize edilir. Test maddesinin uygulanmasını takip eden 30., 75., 120., 180. ve 240. dakikalarda bir süperfüzyon aparatı ile hasar ölçümü yapılır (19). Ayrıca; kornea kalınlığı, opasite ölçümü, fluorescein sızıntısı, doku kalınlığı (şişmesi) ve makroskopik değişiklikler değerlendirilir (43). In vivo Draize test sonuçlarına benzer sonuçlar elde edilmesine karşın, bazı durumlarda farklı sonuçların da elde edilebilme olasılığı vardır. ICE testinin sinıflandırmaya gerek duyulmayan maddeler (GHS [The Globally Harmonized System of Classification and Labelling of Chemicals] Kategorisi yok, irritan olmayan) ile irritan maddelerin (GHS Kategori 1) ayrımını sağlamak açısından başarılı olduğu belirtilmiştir. Katı, sıvı, emülsiyon ve jeller bu test sisteminde kullanılabilirken, gaz ve aerosol tipteki test maddeleri için sisteminin kullanılması henüz uygun değildir $(4,32,43)$.

Sığır korneası opasite ve geçirgenlik testi (BCOP) ilk olarak Muir $(44,45)$ ve Tchao $(46)$ tarafından uygulanmış, Gautheron ve ark. (35) tarafından geliştirilmiştir. Test maddesi izole edilmiş canlı sığır korneasının epitel yüzeyine uygulanır. Test sonunda opasitometre cihazı ile 1şı geçirgenliğindeki azalma ve görünür sşık spektrofotometresi ile de sodyum fluorescein boyasının geçişindeki artış incelenir. Ölçümler sonunda in vitro irritan skoru (IVIS) hesaplanır. IVIS değerine göre test maddesi korozif veya şiddetli irritan olarak değerlendirilir. Şiddetli irritan maddelerin değerlendirilmesinde de bu test kullanılabilir ancak, orta derecedeki irritan maddelerin değerlendirilmesinde başarısız olduğu belirtilmektedir (47). BCOP testi ECVAM, Japonya Alternatif Yöntemler 
Doğrulama Merkezi (Japanese Center for the Validation of Alternative Methods-JaCVAM) ve Kurumlar Arası Alternatif Yöntemler Doğrulama Komitesi (The Interagency Coordinating Committee on the Validation of Alternative Methods-ICCVAM) tarafından birçok kere değerlendirilmiş, irritan ve irritan olmayan maddelerin belirlenmesi için uygun bir yöntem olduğu ifade edilmiştir. Rutin olarak kozmetik ve ilaç geliştirme şirketlerinin kendi laboratuvarlarında kullanilmaktadir (48, 49). BCOP, 2009 yilinda OECD Test Kılavuzu olarak yayınlanmıştır ve 2013 yılında da güncellenmiştir (48).

Organotipik modeller in vivo ve in vitro yöntemler arasında bir sınır teşkil eder ve etik olarak daha ılımlı ve düşük maliyetli yöntemlerdir. Ancak, bu testlerden elde edilen sonuçlar türler arası anatomi ve fizyoloji farklılıklarından dolayı bazı dezavantajlara sahiptir $(50,51)$. Bu testler kısa süreli maruziyetler için uygun olup, uzun süreli maruziyetlerde yeterli değildir (4).

\subsection{Oküler olmayan organotipik modeller}

Koryoallantoik Membran Vasküler Testi (Chorioallantoic Membrane Vascular Assay-CAMVA), aynı zamanda HETCAM testi olarak da bilinmektedir ve ilk olarak Luepe and Kemper (52) tarafından önerilmiştir. CAM, döllenmiş tavuk yumurtası zarı içinde bulunan, vaskülerize solunum zarıdır. Damarsal ve inflamatuvar süreçleri yönüyle tavşan gözlerinin konjunktival dokusuna benzemektedir. Test maddesine maruziyeti takiben, konjunktivada meydana gelen hasarlarla ilgili kalitatif bilgiler verir. Potansiyel kornea hasarında pıhtılaşma değerlendirmesi yapılır (53). CAM modeli vaskülarizasyon değerlendirmesi yapabilmektedir ve bu yönüyle ICE, BCOP ve IRE modellerinden ayrı olarak sinıflandirılmaktadır (17). IRE ve HET-CAM testleri kozmetik bileşenin güvenliliğinin kanıtlanması noktasında destekleyici olarak kullanılan testlerdir.

\section{In vitro TESTLER}

In vitro toksisite testleri hücre ve doku kültürleri kullanılarak gerçekleştirilir. In vivo ve ex vivo yöntemlere göre avantajları vardır. Düşük maliyetli, basit, kolay elde edilebilir sistemlere sahip oldukları için tercih edilir. In vitro sistemler toksisitenin hücresel ve moleküler düzeyde incelenmesine olanak vermektedir (16). Test maddesinin konsantrasyonu, maruziyet süresi ve uygulanan yöntem değiştirilerek çoklu son noktaların değerlendirmesine olanak verir (4).

Birleşmiş Milletler'in Küresel Uyumluluk Sistemi (United Nations Globally Harmonized System-UN GHS) kimyasal maddelerin sınıflandırılması ve etikelenmesi için geliştirilmiştir (54). Gözirritasyonunun değerlendirilmesinde test maddeleri Draize Tavşan Göz Testi sonuçlarına göre Kategori 1 (gözlerde geri dönüşümsüz hasar), Kategori 2A (gözlerde irritan) ve Kategori 2B (gözlerde hafif derecede irritan) olmak üzere siniflandırılmaktadır (Tablo 1). İritan olmayan test maddelerinin UN GHS sistemine göre sinıflandırılması yoktur $(54,55)$. Avrupa Birliği UN GHS sinıflandırma sistemini Avrupa Birliği Kimyasalların Sinıflandirılması, Etiketlenmesi ve Ambalajlanması (European Union Classification, Labelling and Packaging EU CLP) mevzuatının içinde hayata geçirmiştir. UN GHS sisteminde Kategori 2 A ve 2 B sinıfları, EU CLP sisteminde Kategori 2 (gözlerde irritan) olarak birleştirilmiştir (56) Bileşik Devletleri Çevre Koruma Ajansı (US EPA) ise göz irritanı olan kimyasal maddeleri 4 farklı kategoride sınıflandırmıştır (56).

Tablo 1. GHS Sinıflandırma Sistemi

\begin{tabular}{|c|c|}
\hline GHS kategorisi & In vivo Etki \\
\hline 1 & $\begin{array}{l}\geq \text { KO'lu } 1 \text { hayvan } \geq \text { herhangi bir zamandaki } 4 \text { veya } \\
\geq \text { ortalama }{ }^{1} \text { KO'ya sahip } 2 \text { hayvan } \geq 3 \text { veya IR } \geq 1,5 \text { veya } \\
\geq \text { KO veya IR'ye sahip } 1 \text { hayvan } \geq 1 \text { veya KK veya } K K K \geq 2 \text {, ki bunun tersine dönmesi beklenmemektedir, veya } 21 \text { gün içinde } \\
\text { tam olarak tersine dönmez }{ }^{2}\end{array}$ \\
\hline $2 \mathrm{~A}$ & $\geq$ ortalama ${ }^{1} \mathrm{KO}$ veya IR’ye sahip 2 hayvan $\geq 1$ veya KK veya KKK $\geq 2$, ki bu 21 gün içinde tamamen tersine döner ${ }^{2}$ \\
\hline $2 \mathrm{~B}$ & $\geq$ ortalama ${ }^{1} \mathrm{KO}$ veya IR’ye sahip 2 hayvan $\geq 1$ veya $K K$ veya $K K K \geq 2$, ki bu 7 gün içinde tamamen tersine döner ${ }^{2}$ \\
\hline
\end{tabular}

KK: konjonktiva kemozisi; KO: korneal opasite; KKK: konjonktiva kemozisi kızarıklığı GHS: Globally Harmonised System; IR: iritis 1: ortalama değer test malzemesinin yüklemesinden 24,48 ve 72 saat sonraki derecelendirmeye göre hesaplanır.

2: tam geri dönüşüm, 0 puan gerektirir. 
Tablo 2. ECETOC Veritabanı: EPA ve GHS Göz Hasarı Kategorilerinin Karşılaştırmaları

\begin{tabular}{|c|c|c|c|c|c|}
\hline \multirow[b]{2}{*}{ EPA Sinıflandırması } & \multirow{2}{*}{$\begin{array}{c}\text { Madde } \\
\text { Sayıs1 }\end{array}$} & \multicolumn{4}{|c|}{ GHS Sinıflandırması } \\
\hline & & 1 & $2 \mathrm{~A}$ & $2 B$ & Sinıflandırma Yok \\
\hline EPA I & 28 & $\begin{array}{c}27 / 27 \\
(\% 100) \\
\end{array}$ & $\begin{array}{l}0 / 27 \\
(\% 0) \\
\end{array}$ & $\begin{array}{l}0 / 27 \\
(\% 0) \\
\end{array}$ & $\begin{array}{l}0 / 27 \\
(\% 0) \\
\end{array}$ \\
\hline EPA II & 21 & $\begin{array}{c}4 / 20 \\
(\% 20)\end{array}$ & $\begin{array}{l}14 / 20 \\
(\% 70)\end{array}$ & $\begin{array}{c}2 / 20 \\
(\% 10)\end{array}$ & $\begin{array}{c}0 / 20 \\
(\% 00)\end{array}$ \\
\hline EPA III & 42 & $\begin{array}{l}0 / 40 \\
(\% 0)\end{array}$ & $\begin{array}{c}4 / 40 \\
(\% 10)\end{array}$ & $\begin{array}{c}5 / 40 \\
(\% 12)\end{array}$ & $\begin{array}{l}31 / 40 \\
(\% 78)\end{array}$ \\
\hline EPA IV & 47 & $\begin{array}{l}0 / 47 \\
(\% 0)\end{array}$ & $\begin{array}{l}0 / 47 \\
(\% 0)\end{array}$ & $\begin{array}{l}0 / 47 \\
(\% 0)\end{array}$ & $\begin{array}{l}47 / 47 \\
(\% 100)\end{array}$ \\
\hline
\end{tabular}

Kisaltmalar: ECETOC: European Centre for Ecotoxicology anf Toxicology of Chemicals; EPA: Enviromental Protection Agency; GHS: Globally Harmonised System

Alternatif göz irritasyon modellerinden biri olan EYTEX ${ }^{\mathrm{TM}}$ sistemi 1990'lı yıllarda geliştirilmiştir (57-59). EYTEX ${ }^{\mathrm{TM}}$ protokolünün göz irritasyonunun belirlenmesinde düşük güvenirliğe sahip olduğu; ancak oküler toksisite modelleri için bir basamak oluşturduğu belirtilmektedir $(49,60)$. Oküler Irritection Testi, EYTEX ${ }^{\mathrm{TM}}$ sisteminin güncellenmiş halidir. Bu test irritan kimyasal maddelere maruziyeti ile proteinlerin yapısal fonksiyonlarının değişimi sonucu meydana gelen göz irritasyonu ve korneal opasite değişikliklerinin ölçümüne dayanmaktadır (49).

Kısa süreli maruziyet testi (Short Time Exposure- STE), hücre sitotoksisitesi ve canlılı̆̆ının 3-(4,5-Dimetiltiyazol2-yl)-2,5-difeniltetrazolyum bromür (MTT) yöntemi ile ölçüldüğü bir testtir $(38,61,62)$. Bu testte tavşan kornea hücre hatları kullanılır. Test maddesine 15 dakikalık maruziyet söz konusudur. Tüketici ürünlerinin gerçek maruziyet süreleri ile testteki uygulama süresinin benzer olduğu belirtilmektedir. Bu test sistemi aynı zamanda daha hızlı sonuçlar sunmaktadır $(38,62)$.

Sitosensör Mikrofizyometre (CM) yönteminde fare L3929 fibroblast kültürü kullanılmaktadır. İrritan maddelere karşı oluşan cevaplarda $\mathrm{pH}$ metre kullanılarak hücrelerdeki asidite değişiklikleri izlenmektedir. Bu testte bazal metabolik hızdaki azalma hesaplanarak değerlendirme yapılır. CM, şiddetli irritan (GHS Kategori 1) ile irritan olmayan maddelerin tanımlanması için önerilmektedir $(56,63)$. Bu test sistemi ile ilgili taslak bir OECD kılavuzu inceleme altındadır (63). Sitotoksisite ve hücre fonksiyonu temelli yöntemler olan CM, Fluorescein sızıntısı, nötral kırmızı salımı ve kırmızı kan hücresi (Red Blood Cell-RBC) testleri göz üzerine irritan/korozif etkinin değerlendirilmesinde kullanilan tarama testleri olup, irritasyon/korozyon potansiyelini tespit etmek için uygun değildir (47).
Diğer in vitro Alternatif Testler 2005 yılında düzenlenen ECVAM çalıştayında yeniden yapılandırılmış insan doku modelleri (Reconstructed Human Tissue, RhT) test yöntemleri aşağıdan yukarıya yaklaşımın ilk basamağı (bottom-up) ve yukarıdan aşağıya yaklaşımın (top-down) ikinci basamağ1 olarak düşünülen test stratejileridir. Yukarıdan aşağıya yaklaşımlar şiddetli irritan maddelerin tanımlanmasını, aşağıdan yukarıya yaklaşımlar ise irritan olmayan maddelerin tanımlanmasını kapsar $(15,64)$. İki test yöntemi (EpiOcular ${ }^{\mathrm{Tm}}$ EIT ve SkinEthic ${ }^{\mathrm{Tm}} \mathrm{HCE}$ ) bu yaklaşım için uygun görülmüştür. Bu ve bunu destekleyen raporlar (65), iki test yönteminin irritan olan ve irritan olmayan maddelerin ayrılmasında kullanımı ile ilgili güçlü veriler içermektedir. EpiOcular model testinde katı maddeler için daha ileri çalışmalar ve validasyonlar sağlanmıştır. SkinEthic HCE modeli ise, katı maddeler için henüz ileri optimizasyon aşamasındadır. Bu test yöntemleri şiddetli irritan (GHS Kategori 1) ve orta derecede irritan (GHS Kategori 2) test maddelerinin ayrımı için tasarlanmamıştır (56).

\subsection{EpiOcular ${ }^{\mathrm{Tm}}$ EIT RhT test modeli}

Günümüzde çok tabakalı ve karmaşık 3-D in vitro kültür sistemleri mühendisliğinin gelişmesi ile insan kornea epitelini taklit eden standardize dokuların kullanıma girmesi söz konusu olmuştur. Ciddi göz hasarı, test maddesinin gözün ön bölgesine uygulanmasını takip eden 21 gün içinde tam olarak geri dönüşlü olmayan gözde ciddi fiziksel hasar veya görmede bozukluk ile karakterize bir durumdur (54). Kimyasal madde kaynaklı şiddetli göz hasarı/göz irritasyonu, kimyasal maddenin kornea ve/veya konjonktivadan penetre olması ile gözde ortaya çıkan korneal opasitede değişiklik, iritis, konjonktivada 
kızarıklık ve/veya konjonktival kemozis olaylarını içerir. Hücre hasarı, hücre membran lizisi (surfaktanlar, organik solvanlar) makromolekül koagülasyonu (surfaktanlar, organik solventler, asit ve alkaliler), alkilasyon ya da makromoleküllerle kovalent etkileşmeler gibi birçok mekanizma ile gerçekleşebilir $(1,66,67)$.

Bir kimyasal maddenin ciddi göz hasar potansiyeli, esas olarak "ön hasar derecesi" ile belirlenir (23). Bu hasar derecesi hücre ölümünün düzeyi (68), hücrede devam eden hasar yanıtı ve ortaya çıkan sonuçların düzeyi ile ilişkilidir (69). Çok hafif irritasyona neden olan maddeler genelde sadece korneal epitelin yüzeyinde; hafif ve orta irritan maddeler epitel ve stroma yüzeyinde; şiddetli irritan maddeler ise epitel, derin stroma tabakaları ve korneal endotelde hasara neden olur $(19,70)$. Kimyasal maddeyle karşılaşan ilk kornea epitel hücreleri biyolojik rolleri ve gen regülasyonları açısından incelenmiştir (71).

EpiOcular $^{\text {mo }}$ Göz İrritasyon Testi, EURL ECVAM ve Kozmetik Avrupa - Kişisel Bakım Birliği (Cosmetics Europe - The Personal Care Association) tarafindan valide edilmiş bir yöntemdir (72-76). EpiOcular ${ }^{\text {ri }}$ Göz İrritasyon Testi 2015 yılında valide edilmiş ve OECD tarafından kılavuzu yayınlanarak (OECD 492), göz irritasyonunun değerlendirilmesi için önerilen bir yöntem olmuştur (77). EpiOcular modeller günümüzde Draize testi yerine birçok araştırma laboratuvarlarında, kozmetik, kişisel bakım ve kimya şirketleri tarafından kullanılmaktadır (4). Bu nedenle EpiOcular ${ }^{\mathrm{rm}}$ Göz İrritasyon Testi Valide Referans Yöntem (VRM) olarak tanımlanır. Bu testi sınırlayan nokta, EpiOcular ${ }^{\mathrm{Tm}}$ Göz İrritasyon Testi UN GHS sistemi ile şiddetli irritan (Kategori 1) ve irritan (Kategori 2) maddelerin farkının saptanmasında kullanılmak üzere tasarlanmış bir yöntem olmamasıdır. Bu farkın belirlenmesi ancak daha ileri bir test stratejisinin uygulanmasiyla mümkündür (66). Kimyasal maddelerin göz irritasyonu oluşturma ve şiddetli göz irritasyonu oluşturmalarına göre sınıflandırılmasında EpiOcular $^{\mathrm{m}}$ Göz İrritasyon Testi in vitro veya in vivo ek yöntemlerin uygulanmasıyla kesin bir sinıflandırma yapılmasını gerektirir. Bu testler TG [Test Guide] 437,438, 460 ya da 491 kılavuzlarına yayınlanan testlerdir.

$\mathrm{Bu}$ test sisteminin validasyonunda moleküler ağırlıkları, kimyasal yapısı, tipleri ve sınıfları farklı olan çok çeşitli kimyasal ürün üzerinde çalışılmıştır. EpiOcular ${ }^{\mathrm{m}}$ test sisteminin validasyon veri tabanı 113 kimyasal içermekte olup, OECD SAR Toolbax analizine göre 95'i farklı organik fonksiyonel gruba sahiptir $(73,74)$. Ön validasyon (65) ve tam validasyon $(73,75,76)$ çalışmaları EpiOcular ${ }^{\mathrm{m}}$ test sisteminin sıklıkla uygulanmadığ 1 laboratuvarlarda da bu analizin yürütülmesinin mümkün olduğu; ayrıca laboratuvarlar arası ve laboratuvar içinde tekrarlanabilir olduğu gösterilmiştir. Bu çalışmalara dayanarak, EpiOcular ${ }^{\text {mm }}$ test sisteminin tekrarlanabilirlik düzeyi laboratuvarlar arası \%93 iken, laboratuvar içi \%95 seviyesindedir. Validasyon çalışmalarından elde edilen verilere göre (73) EpiOcular ${ }^{\mathrm{mm}}$ test sistemi, in vivo tavşan göz testinden (OECD TG 405) $(11,14)$ elde edilen sonuçların UN GHS sistemine göre sinıflandırılan verilerine göre; \%80 kesinlikte (112 kimyasal maddeye göre), \%63 özgüllükte (55 kimyasal maddeye göre), \%4 yanlış negatif (57 kimyasal maddeye göre) ve \%37 yanlış pozitif orana (55 kimyasal maddeye göre) olduğu bulunmuştur (54). Test maddeleri olarak sıvı, suda çözünebilen ya da çözünemeyen katı maddeler kullanılabilirken, gaz ve aerosol yapıdaki maddeler validasyon çalışmalarında kullanılmamıştır (77).

OECD 492 kılavuzunda detayları verilen EpiOcular ${ }^{\mathrm{TM}}$ Göz İrritasyon Testi, EpiOcular" (OCL-200) insan kornea epitel yapısının histolojik, morfolojik, biyokimyasal ve fizyolojik özelliklerini taklit eden yeniden yapılandırılmış insan kornea epitel doku modeli kullanılarak farklı kimyasal maddelerle indüklenen sitotoksisite aracılı̆̆ıyla göz hasarının belirlenmesi esasına dayanmaktadır (78). Hemotoksilen/Eozin (H/E) boyalı histolojik kesitleri, kullanılan yapısının insan kornea epitelyumuna benzer olduğunu göstermiştir. Büyük çekirdekli bazal hücreleri 5-6 tabakalı hücre katmanlarının altına yerleşik, doku yüzeyinde keratinsiz tabakaya doğru giderek yassılaşan yapılardadır. EpiOcular $^{\mathrm{ru}}$ test edilen maddenin sıvı ya da katı oluşuna göre iki ayrı protokol ile uygulanır (79). Test maddesi en az iki adet dokuya topikal olarak uygulanır. Belirli maruziyet süreleri sonunda doku canlılığı negatif kontrol olarak karşılaştırılarak \% doku canlılığı mitokondriyal dehidrojenaz ile MTT [[(3-(4,5-Dimetiltiazol-2-yl)2,5-difeniltetrazolyum bromür)] indirgenmesine dayalı bir test ile belirlenir $(78,80)$. Hücre canlllığ belirlenen eşik seviyesinin (doku canlılığı $>$ \%60) üzerinde olduğu durumlarda uygulanan test maddesinin sinıflandırılması ve etiketlenmesine gerek duyulmaz. Bu durumda test maddesi "irritan olmayan kimyasal madde" olarak tanımlanır (77).

Diğer bir alternatif 3D yeniden yapılandırılmış insan kornea epitel (HCE) modeli de SkinEthic Laboratuvarı (Fransa) tarafından geliştirmiştir $(81,82)$. Bu model insan gözünün kornea mukoz tabakasıyla aynı yapıdadır. Test maddeleri 
doku yüzeyine 10 dakika ve 60 dakikalık sürelerle uygulanır. Hücre canlılığ $\% 50$ 'nin üzerinde olduğu durumlarda test maddesi "irritan olmayan madde" olarak sinıflandırilır (4). SkinEthic HCE modeli için de EURL ECVAM ve Kozmetik Avrupa tarafından validasyon çalışmaları yapılmıştır $(65,83)$. EpiOcular ${ }^{\mathrm{TM}}$ EIT ve SkinEthic HCE modellerinin karşılaştıııldığı ve yüzün üzerinde kimyasal maddenin denendiği bir çalışmada, iki model ile de yüksek tekrarlanabilirlik (>\%90) elde edilmiştir. EpiOcular ${ }^{\mathrm{TM}}$ EIT sıvı test protokolü tüm kabul kriterlerini karşılarken, SkinEthic HCE protokolü ile katı maddeler için bu kabul kriterleri karşılanamamıştır. SkinEthic HCE modelinin katı maddeler için uygulanması için ileri optimizasyon çalışmaları devam etmektedir (83).

Son zamanlarda Katoh ve arkadaşları tarafından (2012, 2013), LabCyte CORNEA-MODEL (Japanese Tissue Engineering Co., Ltd., Japan) ve yeni 3D yeniden yapılandırılmış insan kornea modeli MCTT-HCE (New 3D Reconstructed Human Cornea Model, MCTT-HCE) (MCTT, Seol, Korea) geliştirilmiştir. $\mathrm{Bu}$ modellerin morfolojik ve histolojik özellikleri de insan korneal epiteli ile benzerlik göstermektedir. LabCyte CORNEA-MODEL'de ideal işlem zamanı, hacim, ileri inkübasyon zamanı ve ylkama prosedürlerinin belirlenmesi için ön validasyon çalışmaları gerçekleşmiştir (84). MCTT-HCE ve LabCyte CORNEA-MODEL'lerin her ikisi de yüksek kesinlik derecesi ile umut verici sonuçlar vermesine rağmen, henüz resmi bir validasyon değerlendirmesine girmemiştir (4).

\subsection{In vitro Alternatif Yöntemlerin Sınırlamaları}

Epitel modeller ile ilgili sınırlandırmalardan biri hücresel izolasyonu engelleyen korneal dokuda başlangıçtaki enzimatik ve mekanistik disasosiasyonun da hücrede farklı birçok cevap oluşturabilecek travmatik uyarıların oluşmasına neden olabilmesidir (16). Bu durum, hücresel yapı bütünlüğünün bozulmasına, inflamatuvar mediatörlerin salgılanmasına ya da hücre farklılaşmasına neden olabilmektedir. Tüm bunlar madde biyokinetiklerinin in vivo ve in vitro sistemlerde farkl olmasina neden olmaktadır. Bu durumda in vitro toksikoloji çalışmalarında kullanılan hücrelerden elde edilecek veri farklılıklarının da göz önünde bulundurulması gerekmektedir (16).

Ölümsüzleştirilmiş epitel hücre hatları güvenilir bir biçimde in vivo kornea hücre davranışlarını her zaman yansıtmayabilir. Örneğin hücre hatları CK 3, 7, 8, 18 ve 19 gibi sitokeratinleri eksprese etmemektedir (13).

Epitel modellerle çalışırken hassas ve çok dikkatli olunması gerekir. Dokular, hasar vermeden ve kuruması engellenerek saklanmalıdır. Kültürde hücre ayrılmaları, deneysel verileri yanlış yorumlamaya neden olabilmektedir (16). Aynı zamanda bazı kimyasal maddeler gözün farklı bölümlerine farklı şekillerde etki edebilmektedir. Ancak, söz konusu modellerde özelllikle hücre-hücre etkileşimlerinde önemli bir nokta olan bu durum hesaba katılamamıştır (85-87). Ayrıca, in vitro hücre yöntemleri hormonel, immün ve nöranal etkileri yeterince yansitmamaktadır. Bu durum, bu testleri basit ve kolay yorumlanabilir yapmasına rağmen, göz gibi özelleşmiş kompleks bir yapı söz konusu olduğunda gerçek etkileşimlerin belirlenmesinde sınırlamalara neden olmaktadır (15).

\section{SONUÇ}

Göz irritasyonunun tayini amacıyla Draize tavşan testleri, günümüzde kozmetik alanının dışında hala kullanılmaktadır. Kozmetik ürünlerde ise in vitro testlerin kullanımı zorunludur. Bununla birlikte, in vitro alternatif testlerin pratikte kullanımı ile ilgili halen sıkıntılar bulunmaktadır (4). Ancak genel bir değerlendirme yapıldığında insan kornea epitelini taklit eden üç boyutlu doku modellerinin genel yapıları, kompozisyonları, biyokimyasal yönleri insan gözüne benzerlik taşır. $\mathrm{Bu}$ modeller birçok toksisite çalışmaları için uygundur (88).

Her ülkenin kendi mevzuatı ve veri gereksinimleri farklı olabilir, Avrupa Birliği birleşik ve güçlü bir yapıdadır, ancak diğer ülkelerde mevzuatlar tek tek ülkenin ihtiyaçlarına göre değerlendirilmektedir. $\mathrm{Bu}$ süreçler oldukça uzun zaman almaktadır. Mevzuatlarda asıl odaklanılan konu insan sağlığının korunmasıdır. In vitro alternatif test teknikleri geliştirilmiş olmakla birlikte, tüm toksikolojik çalışmaları kapsamamaktadır ve ileri çalışmalara ihtiyaç vardır. Alternatif test yöntemlerinin geliştirilmesi amacıyla, bilimsel ve düzenleyici kuruluşlar arasında katılım ve diyaloğun daha da artması gerekmektedir (4).

Yakın gelecekte in vitro yöntemlerin daha da geliştirilmesiyle kullanımlarında artış olacağına inanılmaktadır. Günümüzde, valide yöntemler bulunsa da, ihtiyacın gerektiği şekilde karşılanabilmesi için yeni valide yöntemlerin geliştirilmesi gereklidir (89). 
Traditional and Alternative Methods For the Evaluation of Eye Irritation Potential of Cosmetic Products

\section{ABSTRACT}

For several years, In vivo ocular toxicity tests were used to evaluate the hazard potential of drugs and chemicals that are applied to eye. In ethical terms, eye irritation tests can cause discomfort and pain in laboratory animals. Since $3 \mathrm{R}$ principle has been published, several alternative methods have been developed, validated and accepted by regulatory authorities to evaluate the potential toxicity of chemicals and cosmetics. On March $11^{\text {st }} 2013$, the commercial sales of any types of cosmetics and personal care products tested on animals, were banned in the European Union. Since then, alternative in vitro toxicity tests are used for the safety evaluation of the cosmetics. For the evaluation of the ocular toxicity of chemicals and cosmetics, the In vitro restructured human ocular tissue models are used as an alternative methods. Some of these models are preferred more because of their morphological and physiological similarity to the human eye. In this review, both in vitro and in vivo ocular toxicity tests will be mentioned; newly developed and validated test methods will be evaluated with a comprehensive perspective.

Key Words: Alternative methods, In vitro, eye irritation, cosmetic products

\section{KAYNAKLAR}

1. Hackett RB, McDonald TO. Eye Irritation. In Advances in Modern Toxicology. Editors: Marzulli FN, Maibach HI, Hemisphere Publishing Corporation. Washington, DC, USA. 1991, pp. 749-815.

2. Wilhelmus KR. The Draize eye test. Surv Ophthalmol 2001; 45: 493-515.

3. Shaw A, Balls M, Clothier R, Bateman N. Predicting ocular irritancy and recovery from injury using Madin-Darby canine kidney cells. Toxicol in vitro 1991; 5: 569-71.

4. Wilson SL, Ahearne M, Hopkinson A. An overview of current techniques for ocular toxicity testing. Toxicology 2015;327:3246.

5. Stephens ML, Mak NS. History of the 3Rs in toxicity testing: from Russell and Burch to 21st century toxicology, Reducing, Refining and Replacing the Use of Animals in Toxicity Testing. Editors: Allen D, Walters M, RSC Publishing. Cambridge, UK. 2013, pp. 1-39.

6. Russell WMS, Burch RL, Hume CW. The Principles of Humane Experimental Technique. Methuen, London, UK. 1959.

7. European Commision (EC) Cosmetics Directive: Council Directive of 27 July 1976 on the approximation of the laws of the Member States relating to cosmetic products (76/768/ EEC) 1976.

8. SCCP. The SCCP'S Notes Of Guidance For The Testıng Of Cosmetic Ingredients And Their Safety Evaluation, 6th Revisıon Scientific Committee On Consumer Products 2006.

9. European Union (EU). Council Directive 93/35/EEC of 14 June 1993 amending for the sixth time Directive 76/768/ EEC on the approximation of the laws of the Member States relating to cosmetic products. OJ L151, 1993, 32-7.

10. Rogiers V, Pauwels M. Curr Probl Dermatol 36: Safety Assessment of Cosmetics in Europe. S. Karger, Basel, Switzerland. 2008.

11. Draize JH, Woodard G, Calvery HO. Methods for the study of irritation and toxicity of substances applied topically to the skin and mucous membranes. J Pharmacol Exp Ther 1944; 82: $377-90$
12. Calabrese EJ. Principles of Animal Extrapolation. Wiley Interscience, New York. 1987.

13. Huhtala A, Salminen L, Tähti H. Uusitalo H. Corneal models for the toxicity testing of drugs and drug releasing materials. In: Topics in multifunctional biomaterials and devices. Editors: Ashammakhi N. Biomaterials and Tissue Engineering Group. 2008.

14. Organisation for Economic Co-operation and Development (OECD). Acute Eye Irritation/Corrosion Guideline for Testing of Chemicals No. 405. Organisation for Economic Cooperation and Development, Paris 2014.

15. Barile FA. Validating and troubleshooting ocular İn vitro toxicology tests. J Pharm Toxicol Methods 2010; 61: 136-45.

16. Davila JC, Rodriguez RJ, Melchert RB, Acosta SL. Predictive value of In vitro model systems in toxicology. Annu Rev Pharmacol Toxicol 1998; 38: 63-96.

17. Curren RD, Harbell, JW. Ocular safety: a silent (in vitro) success story. Altern Lab Anim 2002; 30: 69-74.

18. Prinsen MK. The Draize eye test and in vitro alternatives; a left-handed marriage? Toxicol in vitro 2006; 20: 78-81.

19. Maurer JK, Parker RD, Jester JV. Extent of initial corneal injury as the mechanistic basis for ocular irritation: Key findings and recommendations for the development of alternative assays. Regul Toxicol Pharmacol 2002; 36: 106-17.

20. NRC, Principles and Procedures for Evaluating the Toxicity of Household Substances. National Academy of Sciences Publication, Washington, DC. 1977.

21. Griffith JF, Nixon GA, Bruce RD, Reer PJ, Bannan EA. Doseresponse studies with chemical irritants in the albino rabbit eye as a basis for selecting optimum testing conditions for predicting hazard to the human eye. Toxicol Appl Pharmacol 1980; 55: 501-13.

22. Lambert LA, Chambers WA, Green S, Gupta KC, Hill RN, Hurley PM, Lee CC, Lee JK, Liu PT, Lowther DK, Roberts CD, Seabaugh VM, Springer JA, Wilcox NL. The use of lowvolume dosing in the eye irritation test. Food Chem Toxicol 1993; 31: 99-103. 
23. Jester JV, Li L, Molai A, et Maurer JK. Extent of corneal injury as a mechanistic basis for alternative eye irritation tests. Toxicol in vitro 2001; 15: 115-30.

24. Freeberg F, Griffith J, Bruce R, Bay P. Correlation of animal test methods with human experience for household products. Cutan Ocul Toxicol 1984; 3: 53-64.

25. Freeberg F, Hooker D, Griffith J. Correlation of animal eye test data with human experience for household products: an update. Cutan Ocul Toxicol 1986; 5: 115-23.

26. Ghassemi A, Sauers, L, Bruner L, Reer P, Hall R. Demonstrating the human safety of a new household cleaning (HSC) product using alternatives to the Draize eye irritation test. Presentation made at the US Society of Toxicology meeting. 1993

27. The Interagency Coordinating Committee on the Validation of Alternative Methods (ICCVAM). International Association for Soaps, ICCVAM LVET Test Method Evaluation Report: Recommendation to Discontinue Use of the Low Volume Eye Test for Ocular Safety Testing. National Institute of Environmental Heath Sciences, Triangle Park, NC NIH Publication. 2010.

28. Freeberg F, Nixon G, Reer P, Weaver J, Bruce R, Griffith J, Sanders III P. Human and rabbit eye responses to chemical insult. Fundam Appl Toxicol 1986; 7: 626-34.

29. Ubels JL, Clousing DP. In vitro alternatives to the use of animals in ocular toxicology testing. Ocul Surf 2005; 3: 12642 .

30. Bagley DM, Casterton PL, Dressler WE, Edelhauser HF, Kruszewski FH, McCulley JP, Nussenblatt RB, Osborne R, Rothenstein A, Stitzel KA. Proposed new classification scheme for chemical injury to the human eye. Regul Toxicol Pharm 2006; 45: 206-13.

31. Hartung T. Toxicology for the twenty-first century. Nature 2009; 460: 208-12.

32. Organisation for Economic Co-operation and Development (OECD). Test No. 438: Isolated chicken eye test method for identifying ocular corrosives and severe irritants. OECD Guidelines for the Testing of Chemicals, Section 4. OECD Publishing, Paris 2009.

33. Organisation for Economic Co-operation and Development (OECD). Test number 437: Bovine corneal opacity and permeability test metjod for identifying) chemicals induscing serious eye damage and ii) chemicals not requiring classification for eye irritation and serious eye damage. OECD Guidelines for the Testing of Chemicals, Section 4. OECD Publishing, Paris 2009.

34. Burton $\mathrm{AB}$, York M, Lawrence RS. The in vitro assessment of severe eye irritants. Food Cosmet Toxicol 1981; 19: 471-80.

35. Gautheron P, Dukic M, Alix D, Sina JF. Bovine corneal opacity and permeability test: $A n$ in vitro assay of ocular irritancy. Fundam Appl Toxicol 1992; 18: 442-9.

36. Prinsen MK. The chicken enucleated eye test (CEET): A practical (pre)screen for the assessment of eye irritation/ corrosion potential of test materials. Food Chem Toxicol 1996; 34: 291-6.

37. Griffith M, Osborne R, Munger R, Xiong X, Doillon CJ, Laycock NL, Hakim M, Song Y, Watsky MA. Functional human corneal equivalents constructed from cell lines. Science 1999; 286: 2169-72.
38. Takahashi Y, Koike M, Honda H, Ito Y, Sakaguchi H, Suzuki H, Nishiyama N. Development of the short time exposure (STE) test: An in vitro eye irritation test using SIRC cells. Toxicol in vitro 2008 ; 22: 760-70.

39. Organisation for Economic Co-operation and Development (OECD Fluorescein Leakage Test Method for Identifying Ocular Corrosives and Severe Irritants. OECD Guideline for the Testing of Chemicals No. 460. Organisation for Economic Cooperation and Development, Paris, France 2012.

40. Reader SJ, Blackwell V, O'Hara R, Clothier RH, Griffin G, Balls M. Neutral red release from pre-loaded cells as an İn vitro approach to testing for eye irritancy potential. Toxicol in vitro 1990; 4: 264-6.

41. Guo X, Yang XF, Yang Y, Hans R, Cai JH, Xue JY, Tan XH, Xie XP, Xiong, XK, Huang JM. Prediction of ocular irritancy of 26 chemicals and 26 cosmetic products with isolated rabbit eye (IRE) test. Biomed Environ Sci 2012; 25: 359-66.

42. The Interagency Coordinating Committee on the Validation of Alternative Methods (ICCVAM). Editor: N.I.o.E.H. Sciences, NIH Publication. ICCVAM Recommended Test Method Protocol Isolated Rabbit Eye Test Method. National Institute of Environmental Heath Sciences, Triangle Park, NC, 2010, pp. 1-15.

43. Organisation for Economic Co-operation and Development (OECD). Test No. 438: Isolated Chicken Eye Test Method for Identifying i) Chemicals Inducing Serious Eye Damage and ii) Chemicals Not Requiring Classification for Eye Irritation or Serious Eye Damage. OECD Publishing, Paris 2013.

44. Muir C. A simple method to assess surfactant-induced bovine corneal opacity in vitro: Preliminary findings. Toxicol Lett 1984; 22: 199-203.

45. Muir C. Surfactant-induced opacity of bovine isolated cornea: An epithelial phenomenon? Toxicol Lett 1987; 38: 51-4.

46. Tchao R. Trans-epithelial permeability of fluorescein in vitro as an assay to determine eye irritants. In: Alternative Methods in Toxicology. Editor: Goldbery A. Mary Ann Liebert, New York. 1988, pp. 271-283.

47. Türkiye İlaç Ve Tibbi Cihaz Kurumu Kozmetik Ürünler Üzerinde Yapilan Hayvan Deneylerine Alternatif Test Metotlarına İlişkin Kılavuz. PDF dokümanı.

48. Organisation for Economic Co-operation and Development (OECD). In: Guidleines, O. (Ed.), Test No. 437: Bovine Corneal Opacity and Permeability Test Method for Identifying i) Chemicals Inducing Serious Eye Damage and ii) Chemicals Not Requiring Classification for Eye Irritation or Serious Eye Damage. OECD Publishing, Paris 2013.

49. Eskes C, Bessou S, Bruner L, Curren R, Harbell J, Jones P, Kreiling R, Liebsch M, McNamee P, Pape W. Eye irritation. Altern Lab Anim 2005; 33: 47-81.

50. Reichl S, Muller-Goymann CC. The use of a porcine organotypic cornea construct for permeation studies from formulations containing befunolol hydrochloride. Int J Pharm 2003; 250: 191-201.

51. Reichl S, Bednarz J, Muller-Goymann CC. Human corneal equivalent as cell culture model for in vitro drug permeation studies. Br J Ophthalmol 2004; 88: 560-5.

52. Luepke NP, Kemper FH. The HET-CAM test: An alternative to the draize eye test. Food Chem Toxicol 1986; 24: 495-6. 
53. NICEATM, Current Status of in vitro Test Methods for Identifying Ocular Corrosives and Severe Irritants: Hen's Egg Test- Chorioallantoic Membrane Test Method. Editor: D.o.H.a.H. Services, ICCVAM Publication, NIEHS Publication, North Carolina. 2006.

54. United Nations (UN). United Nations Globally Harmonized System of Classification and Labelling of Chemicals (GHS). ST/SG/AC.10/30, Fifth Revised Edition, New York and Geneva: United Nations 2013.

55. European Union (EU). Regulation (EC) No 1272/2008 of the European Parliament and of the 533 Council of 16 December 2008 on classification, labelling and packaging of 534 substances and mixtures, amending and repealing Directives 67/548/EEC and 535 1999/45/EC, and amending Regulation (EC) No. 1907/2006. OJEU L 2008; 353: 1-1354.

56. Globally harmonised system of classification and labelling of chemicals (GHS) United Nations, New York, Geneva 2011, 133-145

57. Courtellemont P, Pannetier M, Biesse JP, Larnicol M, Baret JP, Breda B. Evaluation of the EYTEX(TM) system in the COLIPA eye irritation program. Toxicol in vitro 1999; 13: 295-304.

58. Gordon VC, Kelly CP, Bergman HC. Applications of the EYTEX method. Toxicol in vitro 1990; 4:314-7.

59. Matsukawa K, Masuda K, Kakishima H, Suzuki K, Nakagawa Y, Matsushige C, Imanishi Y, Nakamura T, Mizutani A, Watanabe R, Shingai T, Kaneko T, Hirose A, Ohno Y. Interlaboratory validation of the in vitro eye irritation tests for cosmetic ingredients. (11) EYTEX(TM). Toxicol in vitro 1999; 13: 209-17.

60. Eskes C, Hoffmann S, Facchini D, Ulmer R, Wang A, Flego M, Vassallo M, Bufo M, van Vliet E, d'Abroscat F. Validation study on the Ocular Irritection 1 assay for eye irritation testing. Toxicol in vitro 2014; 28: 1046-65.

61. Kojima H, Hayashi K, Sakaguchi H, Omori T, Otoizumi T, Sozu T, Kuwahara H, Hayashi T, Sakaguchi M, Toyoda A. Second-phase validation study of short time exposure test for assessment of eye irritation potency of chemicals. Toxicol in vitro 2013; 27: 1855-69.

62. Takahashi Y, Hayashi K, Abo T, Koike M, Sakaguchi H, Nishiyama N. The short time exposure (STE) test for predicting eye irritation potential: intra- laboratory reproducibility and correspondence to Globally Harmonized System (GHS) and EU eye irritation classification for 109 chemicals. Toxicol in vitro 2011; 25: 1425-34.

63. Organisation for Economic Cooperation and Development 2012a. Draft OECD Guideline for (OECD). the Testing of Chemicals: The Cytosensor Microphysiometer Test Method: An İn vitro Method for Identifying Ocular 3corrosive and Severe Irritant Chemicals as Well as Chemicals Not Classified as Ocular Irritants. OECD Publishing, Paris 2012.

64. Engelke M, Zorn-Kruppa M, Gabel D, Reisinger K, Rusche B, Mewes K. A human hemi-cornea model for eye irritation testing: quality control of production, reliability and predictive capacity. Toxicol in vitro 2013; 1: 458-68.

65. Pfannenbecker U, Bessou-Touya S, Faller C, Harbell J, Jacob T, Raabe H, Tailhardat M, Alépée N, De Smedt A, De Wever B, Jones P, Kaluzhny Y, Le Varlet B, McNamee P, MarrecFairley M, Van Goethem F. Cosmetics Europe multi-laboratory

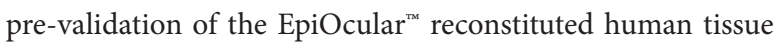
test method for the prediction of eye irritation. Toxicol in vitro 2013; 27: 619-26.

66. Scott L, Eskes C, Hoffmann S, Adriaens E, Alépée N, Bufo M, Clothier R, Facchini D, Faller C, Guest R, Harbell J, Hartung T, Kamp H, Le Varlet B, Meloni M, McNamee P, Osborne R, Pape W, Pfannenbecker U, Prinsen M, Seaman C, Spielman H, Stokes W, Trouba K, Van den Berghe C, Van Goethem F, Vassallo M, Vinardell P, Zuang V. A proposed eye irritation testing strategy to reduce and replace in vivo studies using bottom-up and top-down approaches. Toxicol in vitro 2010; 24: 1-9.

67. Fox DA, Boyes WK. Toxic Responses of the Ocular and Visual System. In Cassaret and Doull's Toxicology: The Basic Science of Poisons. Editor: Klaassen CD. 7th Edition, Withby, ON, McGraw-Hill Ryerson. Canada. 2008, pp. 665-697.

68. Jester JV, Li HF, Petroll WM, Parker RD, Cavanagh HD, Carr GJ, Smith B Maurer JK. Area and depth of surfactant induced corneal injury correlates with cell death. Invest Ophthalmol Vis Sci 1998; 39: 922-36.

69. Jester JV, Petroll WM, Bean J, Parker RD, Carr GJ, Cavanagh $\mathrm{HD}$, Maurer JK. Area and depth of surfactant-induced corneal injury predicts extent of subsequent ocular responses. Invest Ophthalmol Vis Sci 1998; 39: 2610-25.

70. Jester JV. Extent of corneal injury as a biomarker for hazard assessment and the development of alternative models to the draize rabbit eye test. Cutan Ocul Toxicol 2006; 25: 41-54.

71. Castro-Munozledo F. Corneal epithelial cell cultures as a tool for research, drug screening and testing. Exp Eye Res 2008; 86: 459-69.

72. Freeman, SJ, Alépée N, Barroso J, Cole T, Compagnoni A, Rubingh C, Eskes C, Lammers J, McNamee P, Pfannenbecker U, Zuang V. Prospective validation study of reconstructed human tissue models for eye irritation testing. ALTEX 27, Special Issue 2010; 261-266.

73. EC EURL ECVAM. Eye Irritation Validation Study (EIVS): Statistical Analysis of the Data Generated Under SOP ver 8.0 of EpiOcular ${ }^{\mathrm{TM}}$ EIT (Solid Test Substances, Laboratory Beiersdorf), 2014, pp. 21.

74. EC EURL ECVAM. Validation Study Report on the EURL ECVAM - Cosmetics Europe Prospective Validation Study of Reconstructed Human Corneal Epithelium-Based Test Methods for Identifying Chemicals not Requiring Classification and Labelling for Serious Eye Damage/Eye Irritation Testing. 2014.

75. EC EURL ECVAM. (Eye Irritation İn vitro Assay Validation: Selection of Test Item Chemicals (EpiOcular ${ }^{\mathrm{Ta}}$ Eye Irritation Test and SkinEthic ${ }^{\text {Tx }}$ Human Cornea Epithelium). Validation Management Group report. 2014.

76. TNO. Eye Irritation Validation Study on Human Tissue Models: Statistical Analysis and Reporting on the EpiOcular ${ }^{\mathrm{TA}}$ EIT. TNO Report TNO2013 R10396 Final, pp. 165. (Manuscript in Preparation) 2014.

77. Organisation for Economic Cooperation and Development 2012a. Draft OECD Guideline for (OECD). Reconstructed human Cornea-like Epithelium (RhCE) test method for identifying chemicals not requiring classification and labelling 
for eye irritation or serious eye damage No. 492. Organisation for Economic Cooperation and Development, Paris 2015.

78. Kaluzhny Y, Kandárová H, Hayden P, Kubilus J, d’ArgembeauThornton L, Klausner M. Development of the EpiOcular ${ }^{\mathrm{rm}}$ eye rrritation test for hazard identification and labelling of eye iritating chemicals in response to the requirements of the EU cosmetics directive and REACH legislation. Altern Lab Anim 2011; 9: 339-64.

79. Kaluzhny Y, Kandárová H, d’Argembeau-Thornton L, Hayden De Luca J, Hayden P, Hunter P, Klausner M. Optimization of the EpiOcularTM eye irritation test for hazard identification and labelling of chemicals in response to the requirements of the EU Cosmetic Directive and REACH Legislation, Congress of the European Societies of Toxicology (EUROTOX) 2013; 222: 156.

80. Mosmann T. Rapid colorimetric assay for cellular growth and survival: Application to proliferation and cytotoxicity assays. J Immunol Methods 1983; 65: 55-63.

81. Doucet O, Lanvin M, Thillou C, Linossier C, Pupat C, Merlin B, Zastrow L. Reconstituted human corneal epithelium: a new alternative to the Draize eye test for the assessment of the eye irritation potential of chemicals and cosmetic products. Toxicol in vitro 2006; 20: 499-512.

82. Van Goethem F, Adriaens E, Alepee N, Straube F, De Wever B, Cappadoro M, Catoire S, Hansen E, Wolf A, Vanparys P. Prevalidation of a new in vitro reconstituted human cornea model to assess the eye irritating potential of chemicals. Toxicol in vitro 2006; 20: 1-17.

83. Zuang V, Schäffer M, Tuomainen AM, Amcoff P, Bernasconi C, Bremer S, Casati S, Castello P, Coecke S, Corvi R, Griesinger C, Janusch Roi A, Kirmizidis G, Prieto P, Worth A, Munn S,
Berggren E, Whelan M. In: European Commission JRC, Editor: Institute for Health and Consumer Protection, EURL ECVAM Progress Report on the Development, Validation and Regulatory Acceptance of Alternative Methods (20102013). Prepared in the Framework of Directive 76/768/EEC and Regulation (EC) No 1223/2009 on Cosmetic Products. Publications Office of the European Union, Luxembourg, 2013, pp. 1-63.

84. Jung KM, Lee SH, Ryu YH, Jang WH, Jung HS, Han JH, Seok SH, Park JH, Son Y, Park YH. A new 3D reconstituted human corneal epithelium model as an alternative method for the eye irritation test. Toxicol in vitro 2011; 25: 403-10.

85. McLaughlin CR, Tsai RJF, Latorre MA, Griffith M. Bioengineered corneas for transplantation and İn vitro toxicology. Front Biosci 2009; 14: 3326-37.

86. Wilson SE, Liu JJ, Mohan RR. Stromal-epithelial interactions in the cornea. Prog Retin Eye Res 1999; 18: 293-309.

87. Wilson SL, Yang Y, El Haj AJ. Corneal stromal cell plasticity: In vitro regulation of cell phenotype through cell-cell interactions in a three-dimensional model. Tissue Eng Part A 2014; 20: 225-38.

88. Netzlaff F, Lehra CM, Wertzb PW, Schaefera UF. The human epidermis models EpiSkinw, SkinEthicw and EpiDerm: An evaluation of morphology and their suitability for testing phototoxicity, irritancy, corrosivity, and substance transport. Eur J Pharm Biopharm 2005; 60: 167-78.

89. Vinardell MP. The use of non-animal alternatives in the safety evaluations of cosmetics ingredients by the Scientific Committee on Consumer Safety (SCCS). Regul Toxicol Pharmacol 2015; 71: 198-204. 